\title{
An overview of cyanobacterial research and management in South Africa post-2000
}

\author{
William R Harding ${ }^{1 *}$, Timothy G Downing ${ }^{2}$, Catharina E van Ginkel ${ }^{3}$ and Annatjie PM Moolman ${ }^{4}$ \\ ${ }^{1}$ DH Environmental Consulting, PO Box 5429, Helderberg 7135, South Africa \\ ${ }^{2}$ Cyanobacterial Research Group, Nelson Mandela Metropolitan University, Port Elizabeth, South Africa \\ ${ }^{3}$ Resource Quality Services, Department of Water Affairs and Forestry, Roodeplaat, Pretoria, South Africa \\ ${ }^{4}$ Water Research Commission, Pretoria, South Africa
}

\begin{abstract}
The quality of South Africa's water resources is becoming increasingly impaired by eutrophication, to the extent that regional crises now prevail. Thirty-five percent of the total storage is eutrophic to hypertrophic - including grosslyenriched reservoirs that far exceed the globally-accepted definition of hypertrophy. Failing infrastructure contributes to the problem of polluted urban runoff which comprises a significant fraction of flows to inland reservoirs, particularly in the landlocked, economic heartland of the country. In the period post-2000, a number of developments have underpinned the provision of a research and management infrastructure that ensures that South African water resource management structures are capable of dealing with cyanobacterial problems. This paper details the progress and achievements that have been made during this period.
\end{abstract}

Keywords: cyanobacteria, eutrophication, reservoirs, South Africa

\section{Introduction}

South Africa has a proud history of contributing to the global understanding of cyanobacteria, cyanobacterial toxins and the ecological associations of these organisms in eutrophic waters. In particular, research conducted during the mid1970s to early 1980s yielded, inter alia, an array of new information ranging from the molecular structure of microcystin, analytical detection methods for hepatotoxins and details of animal toxicosis spanning domestic animals, livestock and wildlife (Harding and Paxton, 2001). During the 1980s, a time when countries such as the United Kingdom (NRA, 1990; Codd et al., 1994), Australia (DWR, 1992) and the United States of America (e.g. AWWARF, 1995) were expanding their cyanobacterial capacity in response to extremely problematic extant and anticipated algal bloom incidents. The South African authorities tackled the problem of eutrophication by first determining the main contributing factor, namely effluent from wastewater treatment plants (Grobler and Silberbauer, 1985). They then developed, adopted and promulgated the $1 \mathrm{mg} / \ell$ phosphate standard for wastewater effluents $(1 \mathrm{mg} / \ell$ phosphate standard $)$ in seven selected catchments (Anon, 1988). The rationale was to minimise the influx of nutrients in order to manage eutrophication. Since the implementation of the standard during the 1980s the Department of Water Affairs and Forestry (DWAF) has monitored the effectiveness of the standard through the Trophic Status Project (Van Ginkel et al., 2000) but did not support any research focus on eutrophication as a priority issue (Walmsley, 2000). This neglect significantly constrained South Africa's

\footnotetext{
* To whom all correspondence should be addressed.

용 +2721 855-2528; fax: +2721 855-2528; e-mail: info@dhec.co.za

Received 10 February 2009; accepted in revised form 30 April 2009.
}

ability to deal with a burgeoning problem (Walmsley, 2000).

The eutrophication monitoring continued within the historical Trophic Status Project of the Department of Water Affairs and Forestry (Van Ginkel et al., 2000a) and with the implementation of the National Eutrophication Monitoring Programme of the DWAF (Downing and Van Ginkel, 2004; Van Ginkel, 2004a;b; Van Ginkel, 2005; Van Ginkel and Mphumbude, 2006). Conditions in South African water resources have become increasingly impaired over time, with an estimated $35 \%$ of the total impounded storage now classified as eutrophic to hypertrophic - including grossly-enriched reservoirs that far exceed the globally-accepted definition of hypertrophy. This situation has been exacerbated by failing infrastructure, and polluted urban runoff that comprises a significant fraction of the inflows to inland reservoirs (Harding, 2008).

Nationally-driven funding and research was severely, in some areas completely, curtailed. However, some of the larger local authority (municipal) and private water supply utilities, sharing a common concern regarding the need to be knowledgeable about the quality and treatment requirements of their raw potable supplies, established research and monitoring facilities. The City of Cape Town established the first dedicated municipal laboratory in South Africa for the undertaking of routine analyses for cyanotoxins in water supplies; this HPLC-based design later cloned to Rand Water (Gauteng) and to the Water Utilities Corporation of Botswana. The KwaZuluNatal water provider, Umgeni Water, also stepped up their algal toxin monitoring capabilities during the 1990s.

Early into the new millennium, it became apparent that South Africa needed to re-group and re-focus remaining skills and potential within the closely linked fields of eutrophication and cyanobacteria. The incidence and extent of cyanobacteria in surface waters in South Africa are symptomatic of eutrophic conditions. While nutrient management remains the key to address eutrophication, the scale of the problem is such that attention to cyanobacterial research and management issues 
cannot ignored whilst awaiting possible future attenuation of nutrient loads. With this focus in mind, the South African Water Research Commission (WRC) and Department of Water Affairs and Forestry (DWAF) (now Department of Water and Environment Affairs) have, since 2000, funded a number of research programmes aimed at re-equipping South African water resource management with the fundamental tools required for understanding and assessing both cyanobacteria and the underlying cause, eutrophication. Additionally, DWAF, as part of the National Eutrophication Monitoring Programme, monitors phytoplankton composition and numerical densities in 17 water management areas, as well as the presence of toxins in problem reservoirs - using an ELISA-based screening method.

A global commonality to cyanobacterial research is that this science is informed by a small number of research groups, located in various countries. Much of the global knowledge resource for cyanobacteria and cyanotoxin management is localised amongst a small group of individuals, located at universities, research institutes and water management organisations, all sharing an essentially common goal. Research budgets are relatively small, in comparison with other programmes dealing with human and animal toxicology. Opportunities to attract and retain competent researchers are limited. Accordingly, international collaboration, sharing skills and experience, offers a valuable mechanism for coupling scarce skills and resources. The South African approach has been founded on a re-positioning of skills within a framework of international collaboration

\section{The South African research strategy}

The formulation of a research and management strategy, addressing issues of toxic algae in South African surface waters, commenced during 2003. The framework was based on an examination of local needs and research capabilities, coupled to a parallel examination of international approaches, identified via 4components (Harding, 2006):

- Participation with the Global Water Research Coalition (GWRC) Working Group on Cyanobacteria, with workshops held in Adelaide (Australia) and Somerset West (South Africa), respectively, in 2004 and 2007 (the WRC is a GWRC-partner organisation). The Australian workshop identified key research issues, one of which was the preparation of a globally-generic methods manual that addresses all aspects of cyanobacterial monitoring and management response to a toxic event. The workshop held in South Africa during 2007 served to structure the content of the manual and initiate the production of the various chapters.

- Input to the feasibility study for CYANONET, a proposed global network for information and skills sharing on cyanobacterial bloom and toxin risk management (IHP, 2005). Regrettably, this important initiative, upon which a number of regional networks - serving poorly resourced countries - could have been established, was unsuccessful in its attempts to obtain $2^{\text {nd }}$ phase funding from UNESCO.

- Participation in the $6^{\text {th }}$ and $7^{\text {th }}$ meetings of the International Conference on Toxic Cyanobacteria (ICTC) held, respectively, in Bergen, Norway during 2004 and Rio de Janeiro State, Brazil, in 2007, and the $5^{\text {th }}$ International Symposium on beta-methyl amino-alanine (BMAA), held in the USA during 2008.

- Continued interaction with researchers and research groups, both locally and abroad.
The $1^{\text {st }}$ phase of strategic planning, culminating in 2006, is summarised in Harding (2006). This assessment concluded that, while the incidence of cyanobacterial blooms and toxins did not indicate a national crisis, regional problems - particularly within the landlocked economic heartland of the country and, since 2006, within the Kruger National Park, indicated regional crises and probably a national cause for alarm. Emanating from the needs-evaluation process outlined above, a framework incorporating the development of a supportive and guiding research environment, coupled with specific research needs, was formulated. The underlying intention of this planning was to optimally direct the deployment of scarce research funding in order to develop national cooperation and optimally address local needs, as well as to contribute to international research programmes, where appropriate.

The creation of a supportive research environment seeks to integrate the activities of research institutions, water supply authorities, national government and resource agencies in the best possible manner. This approach stressed the need for the creation of a well-equipped national analytical facility - subsequently created at the Cyanobacterial Research Group (CRG) of the Nelson Mandela Metropolitan University (NMMU, Port Elizabeth), working in association with the North-West University (NWU) in Potchefstroom. Encouragement of overlap with related programmes addressing eutrophication and pollution management, development of skills and capacity and, importantly, public education and awareness training were identified as over-arching needs.

\section{Progress and outcomes}

The proposed research strategy (Harding, 2006) embodies 4 core directions, namely:

- Eco-physiology of cyanobacteria and cyanotoxin production - particularly in respect of what triggers toxin production, and why

- Physiology and genetics (population and related phylogenetics)

- Issues surrounding $\beta-\mathrm{N}$-methylamino-L-alanine (BMAA)

- Applied management needs

Since the promulgation of the $1 \mathrm{mg} / \ell$ ortho-phosphorus effluent standard in 1985 (DWAF 1988) DWAF has initiated a eutrophication monitoring programme, known as the Trophic Status Project (TSP). Initially the TSP focused on only the 7 catchments that were included in the $1 \mathrm{mg} / \ell \mathrm{P}$ standard. However, the lack of information on many other South African waters led to the development of a National Eutrophication Monitoring Programme (NEMP) during the late 1990s. This development was undertaken by the DWAF in collaboration with the WRC. This monitoring programme was aimed at introducing monitoring throughout South Africa in all 19 of the Water Management Areas (WMAs).

Following an assessment of the historical TSP condition (Van Ginkel et al., 2000a) and after the outbreak of a Cylindrospermopsis raciborskii bloom in the Orange River (Van Ginkel and Conradie, 2001), the DWAF re-focused monitoring, research and management on the effects of eutrophication. The progressive development of Internal Strategic Plans (ISP) for each WMA also brought the need for eutrophication management to the attention of the DWAF.

The information needs identified by DWAF and the WRC since 2000 were as follows: 
- A need for information on the incidence of cyanobacterial toxins in South African water resources. This shortcoming was partially addressed by a cyanobacterial survey (Van Ginkel, 2004a) and an overview assessment of the eutrophication monitoring programme information (Downing and Van Ginkel, 2004).

- A shortage of human resource capacity at local government level for identifying algal-related problems. This included both the identification of problems in the raw water system (e.g., blooms in dams) and the algae species responsible. This need was originally addressed by providing both assistance in monitoring of raw water systems and information sessions. Additionally, the WRC developed a laboratory methods manual (Swanepoel et al., 2007), an alert levels response framework (Du Preez and Van Baalen, 2006) and DWAF, in collaboration with the North-West University (Potchefstroom), produced an algal identification guide (Janse van Vuuren et al., 2006).

- A shortage of knowledge at stakeholder level regarding the potential health hazards posed by algal blooms to recreational use. This was initially addressed by reporting on the water quality status of a number of impoundments that are extensively used for recreation. The ultimate intention is that such information would be made available to the media. However, an early warning system remains to be developed.

- The lack of predictive capability to assist water treatment utilities in preparing for potentially toxic events remains a major shortcoming. A number of chlorophyll-modelling studies have been completed, but none targeting specific algal species (Rossouw, 1990; Rossouw, 2000). A study jointly funded by the DWAF and WRC investigated the applicability of ecological informatics modelling techniques for use in predicting algal and cyanobacterial blooms (Van Ginkel, 2008). Within this study the hybrid evolutionary algorithm development modelling technique showed potential for future use and needs to be applied on a wider basis. The availability of an internet-based eutrophication assessment model, the Nutrient Enrichment Assessment Protocol, NEAP (Harding, 2008) served to provide a useful management tool for predicting the characteristics of impoundments in terms of risk of eutrophication impairment.

- With the exception of the $1 \mathrm{mg} / \ell \mathrm{P}$ standard, the lack of practical and pragmatic eutrophication management options remains a major concern. The Hartbeespoort Dam Remediation Plan, developed by Harding et al. (2004a;b), included a number of innovative eutrophication management techniques, e.g., bio-manipulation techniques, riparian zone restoration, etc., with bio-manipulation appearing to embody significant potential for in-lake alleviation of eutrophication impacts. A catchment-assessment protocol, focusing on eutrophication issues, has been published (Rossouw et al., 2008). Guidelines for the management of urban impoundments have also been produced (Freeman et al., 2000). During 2008 long distance flow instruments were also deployed in the Rietvlei Dam to investigate the applicability of epilimnion mixing for the prevention of cyanobacterial development in South African reservoirs. The latter study will run for a number of years before substantive conclusions can be drawn.

- Research into the response of immunodilatory assays, targeting the response of pro-inflammatory cytokines (e.g. IL-6), has screened for the efficacy of this biomarker response to cyanotoxins (Pool, 2005). The use of molecular marker (PCR) diagnostic methods has recently received increased attention (e.g. Botha-Oberholster and Oberholster, 2008).

- Research into the effects of bacterial predation on populations of cyanobacteria has been underway in South Africa for a few years. This work has shown that Bacillus mycoides B16 is an ectoparasite and lyses Microcystis aeruginosa under laboratory conditions. This work remains to be evaluated under field conditions (Gumbo, 2006).

- The value of fishery-based manipulation of eutrophic reservoir-lake food webs has shown great promise for alleviating the impacts of sustained nutrient enrichment in many countries. This approach targets the deliberate, high-level removal of the coarse (a.k.a. rough) fish, such as common carp, barbel (catfish) and zooplanktivorous grazers (e.g. Chetia flaviventris), that tend to predominate in impounded, enriched waters. Research on this approach is already at an advanced stage in South Africa (Harding, personal communication).

\section{The Cyanobacterial Research Group (CRG)}

The Cyanobacterial Research Group (CRG) at Nelson Mandela Metropolitan University (Port Elizabeth, NMMU) evolved post-2000 based on the need to produce adequate toxin for extensive toxicological studies (Gehringer et al., 2003a:b;c; Botha et al., 2004a;b; Gehringer et al., 2004; Gehringer et al., 2005). Optimisation of large-scale production and purification of microcystin for these studies required manipulation of environmental conditions. Literature on environmental modulation of microcystin production was, however, highly contradictory and subsequent work at NMMU focused on environmental modulation and the physiological role of microcystin in cyanobacteria. This included analysis of existing data on toxicity and bloom events in existing impoundments (Downing and van Ginkel, 2004) and resulted in identification of the primary environmental modulators of toxin production (Leukes et al., 2003; Downing et al., 2005a;b) and the construction of both conceptual and structured models for toxin production (Downing, 2007). Subsequent laboratory-scale production of pure microcystin at NMMU (Phelan and Downing, 2007) has allowed further investigation of the physiological function of microcystin and yielded results suggesting a role in protection against photo-oxidation by modification of electron transfer within or between photosystems.

In addition to the elucidation of the primary effectors and contributing physical parameters controlling microcystin production, the CRG at NMMU undertook an extensive survey of large raw potable and irrigation water supply dams within South Africa, with the specific intent of isolating and identifying cyanobacteria within these dams to evaluate the diversity and potential toxicity of common isolates and to attempt to evaluate the spread of such organisms by phylogenetic analysis of all isolates. During the sampling period, toxic blooms were infrequent and relatively few toxic strains were isolated. Phylogeographic analysis revealed limited dissemination of strains with similar organisms observed in the same or downstream impoundments only. Current work, using highly iterative palindromic sequence analysis and additional genetic sequence data, is expected to improve the phylogeographic resolution. Additionally, the isolates form the core of the CRG culture collection housed at NMMU, with duplicates of characterised cultures housed at NWU in Potchefstroom. These cultures are 
currently in various stages of characterisation and have been used to screen for the production of neurotoxins, including $\beta$-N-methylamino-L-alanine (BMAA) following the development of a novel LC-MS method for BMAA detection from free-living cyanobacteria (Esterhuizen and Downing, 2008).

\section{Beta-N-methylamino-L-alanine (BMAA)}

During late 2004 it became apparent that the production of $\beta$-N-methylamino-L-alanine (BMAA) by species of cyanobacteria might embody an additional complication to human health. This awareness followed the possible linkage of BMAA to patients suffering from amyotrophic lateral sclerosis/ Parkinsonism dementia complex (ALS/PDC) (and the subsequent discovery that a wide range of cyanobacterial taxa was capable of producing BMAA (Cox et al., 2005).

ALS-PDC is a neurological disease with aspects of amysotrophic lateral sclerosis, Alzheimer's and Parkinson's diseases (Monson et al., 2003). The relationship between BMAA and ALS-PDC was originally linked to the presence of BMAA in cycad seeds and, more recently, to a symbiotic (root symbionts) relationship between the cyanobacterial genus Nostoc with these cycads. Biomagnification of the toxin from the cycads via fruit bats (Banack and Cox, 2003a) to humans resulted in the occurrence of an abnormally high (50 to $100 \mathrm{x}$ normal incidence) incidence of ALS-PDC (Parkinsonism) in the Chamorro community on the island of Guam (Banack and Cox, 2003b). While investigations seeking the cause of this BMAA production have been in progress since the early 1950s (Cox and Sacks, 2002), it was only during 2003 that the link to cyanobacteria was established - when free-living Nostoc populations were found to produce $0.3 \mu \mathrm{g} / \mathrm{g}$ BMAA (Cox et al., 2003). Axenic cultures were subsequently found to produce significantly higher concentrations, $72 \mu \mathrm{g} / \mathrm{g}$ BMAA (Murch et al., 2004a). Subsequent to the discovery of cyanobacterial involvement in BMAA production in Guam, BMAA was detected in two Canadian Alzheimer's patients - this suggesting the possibility of a wider cyanobacterial involvement given their globally-cosmopolitan incidence (Murch et al., 2004b). These findings led to the inclusion of related research within the South African strategic planning (Harding, 2005) - and the research need was subsequently integrated into the NMMU CRG research programme.

After confirming the production of BMAA by free-living cultures of South African cyanobacteria, this method was used to investigate BMAA association with protein using a prokaryotic expression system, yeast and several mammalian cell lines (Downing, 2009). Additionally, aspects pertaining to BMAA uptake, bioaccumulation and biomagnification are currently under investigation (Downing, 2009). This research directly complements ongoing neurotoxicological and ethnobotanical research headed by the Institute of Ethnomedicine in Wyoming, USA and forms part of the multi-disciplinary approach to BMAA research as discussed at the $5^{\text {th }}$ International Conference on BMAA held in Jackson Hole, Wyoming in October 2008. Evaluation of the potential threat posed by BMAA in South African water supplies will depend on an integrated research approach that will include the fundamental biochemistry of the molecule, its ecological fate and possible routes into humans or large animals, potential for bioaccumulation and biomagnification in aquatic ecosystems, toxicology, and both remediation and treatment options.

\section{Rapid test kits for hepatotoxins ('dip-sticks')}

A long-awaited and much needed technology became available during 2008, this being the commercial production of 'dipstick' testers for microcystins and nodularin. A sample of these kits was tested under South African conditions and found to be entirely suitable for the designated purpose (Downing and Harding, 2008). The availability of these test kits now provides the ability to rapidly undertake toxin tests across a wide range of potentially impacted water types - and precludes the often-lengthy delays between sample collection and the results of laboratory analysis. Additionally, veterinary officers and agricultural advisors are now enabled to conduct 'on-the-spot' testing in rural and farm environments, as are water resource managers in remote areas.

\section{Conclusions}

Despite an extended period of inactivity and inattention to eutrophication in South Africa, spanning almost 20 years (Walmsley, 2000), significant practical progress has been made since 2000 in re-equipping a small research and management fraternity with essential tools and protocols for cyanobacterial research and management. Additionally, a range of high-level research outcomes and collaborations have served to maintain South Africa's position on the global research stage.

\section{References}

ANONYMOUS (1988) Special phosphate standard for sensitive catchments. Water Sewage Effl. 8 10-11.

AWWARF (American Water Works Association Research Foundation) (1995) Cyanobacterial (Blue-Green Algal) Toxins: A Resource Guide. AWWARF, Denver, Colorado, USA.

BANACK SA and COX PA (2003a) Biomagnification of cycad neurotoxins in flying foxes: Implications for ALS-PDC in Guam. Neurol. 61 387-389.

BANACK SA and COX PA (2003b) Distribution of the neurotoxic nonprotein amino acid BMAA in Cycas micronesia. Bot. J. Linn. Soc. 143 165-168.

BOTHA-OBERHOLSTER A-M and OBERHOLSTER PJ (2008) PCR Based Markers for Detection and Identification of Toxic Cyanobacteria. WRC Report No. 1501/1/08. Water Research Commission, Pretoria, South Africa.

BOTHA N, GEHRINGER MM, DOWNING TG, VAN DE VENTER $M$ and SHEPHARD E (2004a) The role of microcystin-LR in the induction of apoptosis and oxidative stress in $\mathrm{CaCo}_{2}$ cells. Toxicon 43 85-92.

BOTHA N, VAN DE VENTER M, DOWNING TG, SHEPHARD E and GEHRINGER MM (2004b) The effect of intraperitoneally administered microcystin-LR on the gastrointestinal tract of Balb/c mice. Toxicon 43 251-254.

CODD GA, JEFFRIES TM, KEEVIL CW and POTTER E (1994) Proc First International Symposium on Detection Methods for Cyanobacterial (Blue-Green Algal) Toxins. 27-29 September 1993, University of Bath, UK. Royal Society of Chemistry, Cambridge.

COX PA and SACKS OW (2002) Cycad neurotoxins, consumption of flying foxes, and ALS-PDC disease in Guam. Neurol. 58 956-959.

COX PA, BANACK SA and MURCH SJ (2003) Biomagnification of cyanobacterial neurotoxins and neurodegenerative disease among the Chamorro people of Guam. PNAS 100 13380-13383.

COX PA, BANACK SA, MURCH SJ, RASMUSSEN U, TIEN G, BIDIGARE RR, METCALF JS, MORRISON LF, CODD GA and BERGMAN B (2005) Diverse taxa of cyanobacteria produce ß-N-methylamino-L-alanine, a neurotoxic amino acid. PNAS 102 5074-5078.

DOWNING TG (2007) A Model for Environmental Regulation of Microcystin Production by Microcystis. WRC Report No. 
1401/1/07. Water Research Commission, Pretoria, South Africa. DOWNING TG and VAN GINKEL CE (2004) Cyanobacterial Monitoring 1990-2000: Evaluation of SA Data. WRC Report No. 1288/1/04. ISBN No. 1-77005-012-6. Pretoria, South Africa.

DOWNING TG, SEMBER CS, GEHRINGER MM and LEUKES W (2005a) Medium N:P ratios and specific growth rate comodulate microcystin and protein content in Microcystis aeruginosa PCC7806 and M. aeruginosa UV027. Microb. Ecol. 49 468-73

DOWNING TG, MEYER C, GEHRINGER MM and VAN DE VENTER M (2005b) Microcystin content of Microcystis aeruginosa is modulated by nitrogen uptake rate relative to specific growth rate or carbon fixation rate. Environ. Toxicol. 20 257-262.

DOWNING TG and HARDING WR (2008) Evaluation of Abraxis Microcystin Test Strips. DH Environmental Consulting Report to Abraxis USA and the Water Research Commission, Pretoria, South Africa. DH Environmental Consulting, Somerset West, South Africa.

DOWNING TG (2009) Personal communication. Cyanobacterial Research Group, Nelson Mandela Metropolitan University, Port Elizabeth, South Africa.

DU PREEZ H and VAN BAALEN L (2006) Generic Incident Management Framework for Toxic Blue-Green Algal Blooms, for Application by Potable Water Suppliers. WRC Report No. TT 263/06). Water Research Commission, Pretoria, South Africa.

DWAF (Department of Water Affairs and Forestry) (1988) Important announcement on implementation of the special phosphate standard in sensitive catchments. IMIESA (Johannesburg), 335.

DWR (Department of Water Resources) (1992) Blue-Green Algae. Final Report of the New South Wales Blue-Green Algae Task Force. Department of Water Resources, Paramatta, New South Wales, Australia.

ESTERHUIZEN M and DOWNING TG (2008) $\beta$-N-methylamino-Lalanine (BMAA) in novel South African Cyanobacterial isolates. Ecotoxicol. Environ. Safety 71 309-313.

FREEMAN MJ, HOWARD MR and WIECHERS HNS (2000) The Management of Urban Impoundments in South Africa. Volume 2. Guideline Manual. WRC Report No. TT 119/00. Water Research Commission, Pretoria, South Africa.

GEHRINGER MM, DOWNS KSS, DOWNING TG, NAUDĒ E and SHEPHARD E (2003a) An investigation into the effect of selenium supplementation on microcystin hepatotoxicity. Toxicon $\mathbf{4 1}$ 451-458.

GEHRINGER MM, GOVENDER S, SHAH M and DOWNING TG (2003b) An investigation of the role of vitamin $E$ in the protection of mice against microcystin toxicity. Environ. Toxicol 18 142-148.

GEHRINGER MM, KEWADA, V COATES N and DOWNING TG (2003c) The use of Lepidium sativum in a plant bioassay system for the detection of microcystin-LR. Toxicon 41 871-876.

GEHRINGER MM, SHEPHARD E, DOWNING TG, WIEGAND C and NIELAN BA (2004) An investigation into the detoxification of microcystin-LR by the glutathione pathway in Balb/c mice. Int. J. Biochem. Cell Biol. 36 931-941.

GEHRINGER MM, MILNE P, LUCIETTO F and DOWNING TG (2005) Comparison of the structure of key variants of microcystin to vasopressin. Environ. Toxicol. Pharmacol. 19 297-303.

GUMBO JR (2006) Antagonism of Bacillus spp. towards Microcystis aeruginosa. Ph.D Thesis, Department of Microbiology and Plant Pathology, University of Pretoria, South Africa.

HARDING WR and PAXTON BR (2001) Cyanobacteria in South Africa: A Review. WRC Report No. TT 153/01.Water Research Commission, Pretoria, South Africa. ISBN 1868457745

HARDING WR, THORNTON JA, STEYN G, PANUSKA J and MORRISON IR (2004a) Hartbeespoort Dam Remediation Project (Phase I). Action Plan (Volume I) Final Report. Department of Agriculture, Conservation, Environment and Tourism Project 58/2003. 158 pp.

HARDING WR, THORNTON JA, STEYN G, PANUSKA J and MORRISON IR (2004b) Hartbeespoort Dam Remediation Project (Phase II). Action Plan (Volume II) Final Report. Department of Agriculture, Conservation, Environment and Tourism Project $58 / 2003.73 \mathrm{pp}$
HARDING WR (2005) Motivation to the Water Research Commission for an Initial Screening of South African Cyanobacterial Populations for BMAA Production. DH Environmental Consulting, Somerset West, South Africa, July 2005.

HARDING WR (2006) A Research Strategy for the Detection and Management of Algal Toxins in Water Sources. WRC Report No. TT 277/06. Water Research Commission, Pretoria, South Africa.

HARDING WR (2008) Cited in: Rossouw JN, Harding WR and Fatoki OS (2008) A Guide to Catchment-Scale Eutrophication Assessments for Rivers, Reservoirs and Lacustrine Wetlands. WRC Report No. TT 352/08. Water Research Commission, Pretoria, South Africa.

HARDING WR (2008) Eutrophication Challenges in South Africa. SIL News 5314.

IHP (INTERNATIONAL HYDROLOGICAL PROGRAMME) (2005) CYANONET: A Global Network for Cyanobacterial Bloom and Toxin Risk Management. Initial Situation Assessment and Recommendations. IHP-VI. Technical Documents in Hydrology 76. UNESCO, Paris.

JANSE VAN VUUREN S, TAYLOR J, GERBER A and VAN GINKEL C (2006) Easy Identification of the Most Common Freshwater Algae. A Guide for the Identification of Microscopic Algae in South African Freshwaters. North-West University, Potchefstroom, South Africa. ISBN 0-621-35471-6.

LEUKES WD, STRONG J and DOWNING TG (2003) Development of a Membrane Photobioreactor for the Study of Microcystin Production by Cyanobacteria. WRC Report No. 1103/1/03. Water Research Commission, Pretoria, South Africa. ISBN 1-77005-076-0.

MONSON CS, BANACK SA and COX PA (2003) Conservation implications of Chamorro consumption of flying foxes as a possible cause of amyotrophic lateral sclerosis-Parkinsonism dementia complex in Guam. Conserv. Biol. 17 678-686.

MURCH SJ, COX PA and BANACK SA (2004a) A mechanism for slow release of biomagnified cyanobacterial neurotoxins and neuro-degenerative disease in Guam. PNAS 101 12228-12231.

MURCH SJ, COX PA, BANACK SA, STEELE JC and SACKS OW (2004b) Occurrence of $\beta$-methylamino-L-alanine (BMAA) in ALS/ PDC patients from Guam. Acta. Neurol. Scand. 110 267-269.

NRA (NATIONAL RIVERS AUTHORITY) (1990) Toxic Blue-Green Algae. National Rivers Authority Report, Water Quality Series No 2. $125 \mathrm{pp}$.

PHELAN RR and DOWNING TG (2007) Optimization of laboratory scale production of microcystin LR by Microcystis aeruginosa PCC 7806. J. Afr. Biotechnol. 6 2541-2548.

POOL EJ (2005) IL-6 as Biomarker for the Immunodilatory Effects of Microcystins. WRC Report No. 1200/1/05. Water Research Commission, Pretoria, South Africa.

ROSSOUW JN (1990) The Development of Management Orientated Models for Eutrophication Control. WRC Report No. 174/1/90. Water Research Commission, Pretoria, South Africa.

ROSSOUW JN (2000) An Extension of Management Orientated Models for Eutrophication Control. WRC Report No. 266/1/01. Water Research Commission. Pretoria, South Africa. 69pp.

SWANEPOEL A, DU PREEZ H, SCHOEMAN C, JANSE VAN VUUREN S and SUNDRAM A (2007) Condensed Laboratory Methods for Monitoring Phytoplankton, Including Cyanobacteria in South African Freshwaters. WRC Report No TT 323/08 (Project K5/1533). Water Research Commission, Pretoria South Africa. $107 \mathrm{pp}$

VAN GINKEL CE, HOHLS BC, BELCHER A and GERBER A (2000) Assessment of the Trophic Status Project, Internal IWQS and DWAF Report No. N/0000/00/DEQ/1799.

VAN GINKEL CE and CONRADIE B (2001) Potential Toxic Algal Incident in the Orange River, Northern Cape, 2000. Draft Report No. N/D801/12/DEQ/0800. Institute for Water Quality Studies, Department of Water Affairs and Forestry, Pretoria.

VAN GINKEL CE (2004a) A National Survey of the Incidence of Cyanobacterial Blooms and Toxin Production in Major Impoundments. Internal Report No. N/0000/00/DEQ/0503. Resource Quality Services, Department of Water Affairs and Forestry. Pretoria.

VAN GINKEL CE (2004b) Assessment of the National Eutrophication Monitoring Programme 2003. Internal Report No. N/0000/00/ 
DEQ/0404 for the Department of Water Affairs and Forestry, South Africa.

VAN GINKEL CE (2005) National Assessment Report. National Eutrophication Monitoring Programme 2004. Internal Report No. N/0000/00/DEQ/0305 for the Department of Water Affairs and Forestry, South Africa.

VAN GINKEL CE (2008) Investigating the Applicability of Ecological Informatics Modelling Techniques for Predicting harmful Algal
Blooms in Hypertrophic Reservoirs of South Africa. Ph.D. Thesis, North-West University, Potchefstroom, South Africa.

VAN GINKEL CE and MPHUMBUDE P (2006) Annual Assessment Report - National Eutrophication Monitoring Programme 2005. Internal Report No. N/0000/00/DEQ/0706 for the Department of Water Affairs and Forestry, South Africa.

WALMSLEY RD (2000) Perspectives on Eutrophication of Surface Waters: Policy/Research Needs in South Africa. WRC Report No. KV 129/00. Water Research Commission, Pretoria, South Africa. 